\title{
The study of biogenic iron oxide nanoparticles effects on iron status in male rabbits infected with $T$. evansi
}

\author{
M.A. Al-Qayim ${ }^{1 \oplus, \text { L.H. Altaie }}{ }^{2} \odot$ and L.S. Ghali ${ }^{3 \oplus}$ \\ ${ }^{1}$ Department of Physiology, Biochemistry, and Pharmacology, College of Veterinary Medicine University of Baghdad, \\ ${ }^{2}$ Departement of Sonar and X-Ray, Technical Medical College, Alfarahidi University, ${ }^{3}$ Central Veterinary Laboratory, \\ Agricultural Directory in Baghdad, Baghdad, Iraq
}

\begin{tabular}{l} 
Article information \\
\hline Article history: \\
Received October 31, 2021 \\
Accepted December 17, 2021 \\
Available online December 11, 2021 \\
\hline Keywords: \\
Iron oxide nanoparticles \\
Osmotic resistance \\
Trypanosma evansi \\
\\
\hline Correspondence: \\
M.A. Al-Qayim \\
dr.majeda@ covm.uobaghdad.edu.iq
\end{tabular}

\begin{abstract}
The present study aimed to evaluate the effects of propolis-iron oxide nanoparticles in eliminating the $T$. evansi parasite and rehome stasis of deleterious iron status in experimentally infected rabbits. Twenty male rabbits were divided into equal four groups $(\mathrm{n}=5)$. the $1^{\text {st }}$ group as Control negative, $2^{\text {nd }}$ control positive, $3^{\text {rd }}$ trypanosomiasis and treated with propolis iron oxide nanoparticles, and $4^{\text {th }}$ trypanosomiasis and treated with diminazene, $2^{\text {nd }}, 3^{\text {rd }}$, and $4^{\text {th }}$ groups were inoculated with T. evansi, and were checked for the onset of parasitemia. After 15 of the onset of parasitemia $3^{\text {rd }}$ group was treated with propolis- iron-oxide nanoparticles $30 \mathrm{mg}$ iron $/ \mathrm{kg} \mathrm{BW}$, and $4^{\text {th }}$ group was treated with diminazene drug with a single dose $3.5 \mathrm{mg} / \mathrm{kg}$ BW. The result showed that experimentally infection with $T$. evansi caused a significant decrease of serum iron and ferritin and a significant increase in total iron-binding capacity and unsaturation iron-binding capacity, as well erythrocytes fragility, bilirubin totally and partially. Treatment with propolis-iron oxide nanoparticles improved iron status parameters to semi-normal values much better than diminazene drug, in addition, reduced the total bilirubin concentration and osmotic fragility of erythrocytes toward a normal state. It can be concluded that the propolis-iron oxide nanoparticles proved successfully rebalancing iron status and eliminating the parasite and making iron available.
\end{abstract}

DOI: 10.33899/ijvs.2021.132058.2039, (CAuthors, 2021, College of Veterinary Medicine, University of Mosul.

This is an open access article under the CC BY 4.0 license (http://creativecommons.org/licenses/by/4.0/).

\section{Introduction}

Trypanosomosis is a worldwide diseases caused by infection of living organisms by trypanosomes parasites, it is an endemic disease in many parts of the world especially in tropical countries like Iraq. Trypanosomiasis caused by the hemoflagelate protozoa that infect a broad types of mammalian (1) and even gees (2).

Anemia is one of the most common symptoms of trypanosomiasis, results from various factors among them the most important is the iron homeostasis dysregulation, however the molecular mechanism is not yet explained (3). T. evansi cause anemia defined by reduction in total serum iron, ferritin, and transferrin saturation (4).
Nanobiotechnology, a unique therapeutic alternative through the repositioning of existing medications and directed drug delivery in treatment of trypanosomiaisis $(5,6)$. The propolis, the resin compound, the third product of bees for protection of and sealing the beehive (7), with high contents of phenolic groups act as antitrypanosomal agent (8).

The application of propolis is free from hepatic or kidney side effects (9). The Propolis mediated IONPs biosynthesis improved iron homeostasis in iron deficiency anemia (10).

Only few drugs have been approved for the treatment of trypanosomiasis (11). Depending on the hypothesis that the large parasite needs iron, there is now a new strategy to treat infections with the parasite by decrease iron availability to 
parasite, using iron chelating agent leading to parasite iron deprivation consider as treatment (4) Hereby, the Propolis iron oxide nanoparticles could be considered as a dual target use, $1^{\text {st }}$ for treatment of anemia, $2^{\text {nd }}$ for killing the trypanosome.

The application of iron oxide nanoparticles $\left(\mathrm{IONP}_{\mathrm{S}}\right)$ as a drug form to treat anemia is a novel drug delivery system, the Propolis mediated IONPs biosynthesis improved iron homeostasis in iron deficiency anemia (10).

Accordingly, the present study designed to explore the possibility of using Propolis iron oxide nanoparticles ( $\mathrm{Pr}-$ $\mathrm{IONP}_{\mathrm{S}}$ ) as a drug to control the growth and proliferation of the parasite in a condition used to treat iron deficiency anemia caused by the experimentally trypanosomiasis in rabbits.

\section{Material and methods}

\section{Biosynthesis of Iron Oxide Nanoparticles (IONPs)}

IONPS prepared by using aqueous macerated propolis solution as reducing agent for the mixture of ferric and ferrous chloride following the procedure of Al-Hussain and Al-Qayim M.2017 (12). The prepared nanoparticles (IONPs) were sterilized by autoclave.

\section{Isolation of T. evansi parasite}

The parasite was isolate from +ve infected camel at AlNajaf city- Iraq, the most endemic area for trypanosomiasis. Presence of the parasite in infected camels confirmed as by the study of blood film stained with Giemsa staining technique. $\mathrm{O} .3 \mathrm{ml}$ of infected camel's blood was inoculated via $\mathrm{i} / \mathrm{p}$ rout to mice for activation and preservation of the parasite.

\section{Experimental design}

Twenty local breeds, male rabbits with age range between 3-5 months were divided into four equal groups, $1^{\text {st }}$ Control Negative for trypanosomiasis (C-ve), $2^{\text {nd }}$ Group Control Positive for trypanosomiasis $(\mathrm{C}+\mathrm{ve}), 3^{\text {rd }}$ Group trypanosomiasis and Pr-IONPs (Tr-Pr-IONP), and $4^{\text {th }}$ Group trypanosomiasis and diminazene (Tr-Dim group).

Trypanosomiasis experimentally induced in rabbits of $2^{\text {nd }}, 3^{\text {rd }}, 4^{\text {th }}$ groups by intra peritoneal $(\mathrm{i} / \mathrm{p})$ injection of $0.3 \mathrm{ml}$ from the infected mice blood with parasitemia of $10^{5} \mathrm{~s} / \mathrm{ml}$. Treatment of trypanosomiasis: after 5, 10, 15 days of $T$. evansi infection infected rabbits were examined for conformation of parasitemia via blood film giemsa stained.

Treatment start after 15 days of infection, $3^{\text {rd }}$ group was given Pr-IONPs via i $/ \mathrm{p}$ a double dosages of iron $(30 \mathrm{mg} / \mathrm{kg}$ ) by 7 days interval (10), $4^{\text {th }}$ group was treated by single dosage diminazene drug $(3.5 \mathrm{mg} / \mathrm{kg})$. Giemsa stained blood film were performed weekly to confirm the presence of the parasitemia. Blood samples were collected at the $30^{\text {th }}$ days of experiment by cardiac puncture.
Body weight changes estimated by subtracting final body weight at $30^{\text {th }}$ day from initial weight at $1^{\text {st }}$ day of experiment.

\section{Iron Status measurements}

Concentration of total serum iron (TSI) $\mu \mathrm{g} / \mathrm{dl}$, Total iron binding capacity (TIBC) $\mu \mathrm{g} / \mathrm{dl}$, ferritin, and Bilirubin measured by spectrophotometric method using enzymatic assay kit (human, Germany).

Unsaturated iron binding capacity (UIBC) $\mu \mathrm{g} / \mathrm{dl}$ calculated from the following equation (13): UIBC $(\mu \mathrm{g} / \mathrm{dl})$ $=$ Total serum Iron concentration $(\mu \mathrm{g} / \mathrm{dl})$-TIBC $(\mu \mathrm{g} / \mathrm{dl})$ Equation 1 Transferrin saturation \% (TfS): Transferrin saturation calculated by equation: $\mathrm{TfS}(\%)=$ Total serum iron - Total iron binding capacity X 100 Equation 2.

\section{Osmotic Fragility test of RBCs}

Osmotic fragility test is done to estimate the membrane integrity of red blood cells (RBCs), measure the ability of RBCs to resistance the hemolysis when exposed to hypotonic solution with different concentration.

Calculated the percentage of hemolysis of red blood cells (RBCs), according to the following equation: RBCs hemolysis $(\%)=$ absorbance of sample at $540 \mathrm{~nm}$ absorbance of blank $(\mathrm{NaCl}) \times 100 \%$ Equation 1

\section{Bilirubin}

Serum Total Serum Bilirubin (TSB) and direct Bilirubin concentration measured by spectrophotometric method by using specialized kit (human, Germany).

\section{Results}

\section{Clinical signs and iron status}

Weekly blood tests can help to track infection rates and monitor the effectiveness of treatment in eliminating parasites. Trypanosoma evansi infected rabbits showed reduced appetite or varying degrees of emaciation, stress and fatigue like behavior represented by less movement, always tend to recombinant, with aggressive behavior. These clinical signs were gradually toward normal state aftre tratment of each group, coincided with the parasite disappearance in blood film specially when treated with Iron Oxide Nanoparticles compared with diminazene drug. Results in Figure 1 showed significant reduction in body weight of $\mathrm{C}+\mathrm{ve}$, and Tr. Dim groups. Treatment with PrIONPs lead to no significant improvement in body weight, in compare with $\mathrm{C}$-ve group.

Iron status measurements values summarized in Table 1. Results revealed significant $(\mathrm{P}<0.05)$ decreased in total Serum iron (TSI), Transferrin saturation, Ferritin concentration and significant $(\mathrm{P}<0.05)$ increased in total iron binding capacity (TIBC), unsaturated iron binding capacity (UIBC) of group +ve positive when compare with C-ve. 


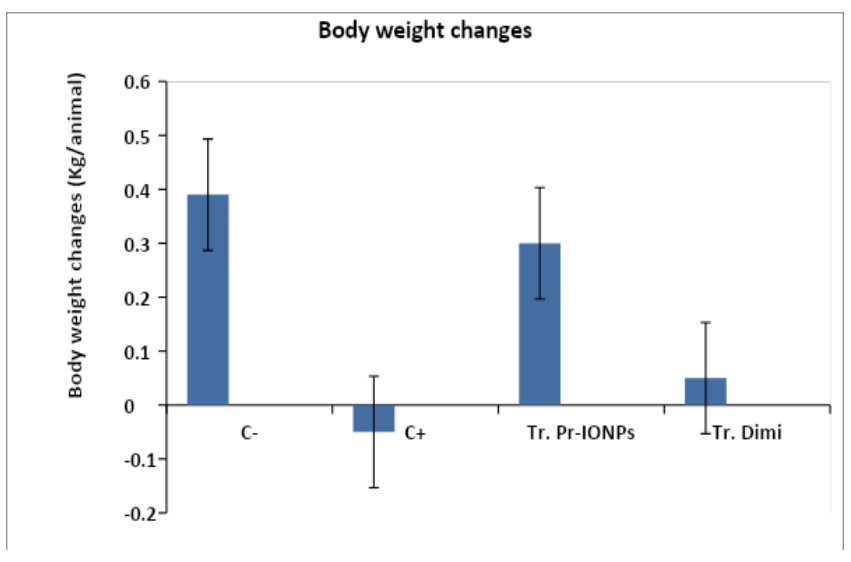

Figure 1: Effects of IONPs treatment on body weight changes in experimentally trypanosomiasis compared with Diminazean drug.

\section{Bilirubin Concentration $(\mathrm{mg} / \mathrm{dl})$ and Erythrocyte Osmotic Fragility}

Total, conjugated and unconjugated Bilirubin increased significantly $(\mathrm{P}<0.05)$ in $\mathrm{C}+\mathrm{ve}$ group as shown in Table 2. Results showed treatment of both groups, Tr. Pr-IONPs \& Tr. Dimi, reduced bilirubin to semi normal as in C-ve.

Osmotic fragility in erythrocytes reflects the effects of the parasites (Trypanosoma) on cell wall integrity of erythrocytes (Table 3). There was significant increase in RBCs hemolysis of the $\mathrm{C}+\mathrm{ve}$ group in $0.1,0.3$, and $0.5 \%$ $\mathrm{NaCl}$ solutions, compared with $\mathrm{C}$-ve this ratio of hemolysis was reduced in PR-IONPs treated animals particularly at 0.1 \& $0.3 \%$ Pr-IONPs keep hemolysis ratio in normal values in spite of the infection. At $0.9 \% \mathrm{NaCl}$ or normal saline PrIONPs showed the lowest RBCs hemolysis ratio.

Immunological evaluation of $\mathrm{IONP}_{\mathrm{S}}$ treatment in $\mathrm{IgG}$ protein in experimentally trypanosomiasis compared with Diminazene Drug, $\mathrm{IgG}$ concentration $(\mathrm{mg} / \mathrm{ml})$ as shown in Figure 2.

Table 1: Changes in some peripheral and central iron status parameters

\begin{tabular}{lccccc}
\hline Groups treatment & S.I. $(\mu \mathrm{g} / \mathrm{dl})$ & TIBC $(\mu \mathrm{g} / \mathrm{dl})$ & U.I.B.C. $(\mu \mathrm{g} / \mathrm{dl})$ & T.S. $(\%)$ & Ferritin $(\mu \mathrm{g} / \mathrm{l})$ \\
\hline C-ve & $126.12 \pm 2.45^{\mathrm{A}}$ & $250.23 \pm 3.62^{\mathrm{C}}$ & $130.11 \pm 4.92^{\mathrm{C}}$ & $49.27 \pm 1.33^{\mathrm{A}}$ & $963.23 \pm 32.83^{\mathrm{AB}}$ \\
C+ve & $95.81 \pm 2.75^{\mathrm{C}}$ & $303.39 \pm 3.63^{\mathrm{A}}$ & $207.57 \pm 5.83^{\mathrm{A}}$ & $31.62 \pm 1.18^{\mathrm{C}}$ & $599.79 \pm 25.44^{\mathrm{C}}$ \\
Tr. Pr-IONPs & $125.67 \pm 2.85^{\mathrm{A}}$ & $248.07 \pm 4.04^{\mathrm{C}}$ & $122.40 \pm 6.27^{\mathrm{C}}$ & $50.76 \pm 1.80^{\mathrm{A}}$ & $1040.43 \pm 30.0^{\mathrm{A}}$ \\
Tr. Dimi & $117.23 \pm 5.14^{\mathrm{B}}$ & $272.40 \pm 4.71^{\mathrm{B}}$ & $152.16 \pm 7.87^{\mathrm{B}}$ & $43.49 \pm 2.15^{\mathrm{B}}$ & $894.08 \pm 42.13^{\mathrm{B}}$ \\
LSD & 8.602 & 14.214 & 18.327 & 4.329 & 96.77 \\
\hline
\end{tabular}

Different letters denoted significant differences at $(\mathrm{P}<0.05)$.

Table 2: Effects of Pr-IONP S treatment on total, conjugated, and unconjugated Bilirubin (mg/dL)

\begin{tabular}{lccc}
\hline Groups & Total Bilirubin & Conjugated Bilirubin & Un-conj. Bilirubin \\
\hline C-ve & $1.45 \pm 0.05^{\mathrm{B}}$ & $0.91 \pm 0.05^{\mathrm{B}}$ & $0.54 \pm 0.05^{\mathrm{B}}$ \\
C+ve & $2.14 \pm 0.07^{\mathrm{A}}$ & $1.20 \pm 0.03^{\mathrm{A}}$ & $0.94 \pm 0.05^{\mathrm{A}}$ \\
Tr. Pr-IONPs & $1.41 \pm 0.04^{\mathrm{B}}$ & $0.84 \pm 0.03^{\mathrm{C}}$ & $0.66 \pm 0.04^{\mathrm{B}}$ \\
Tr. Dimi & $1.62 \pm 0.03^{\mathrm{AB}}$ & $0.92 \pm 0.03^{\mathrm{B}}$ & $0.66 \pm 0.04^{\mathrm{B}}$ \\
LSD & 0.149 & 0.131 & 0.150 \\
\hline
\end{tabular}

Different letters denoted significant differences at $(\mathrm{P}<0.05)$.

Table 3: Protective role of $\mathrm{IONP}_{\mathrm{S}}$ and diminazene drug in $\mathrm{RBC}_{\mathrm{S}}$ hemolysis resistance against $T$. evansi effects

\begin{tabular}{lcccc}
\hline $\mathrm{NaCl}$ Con. \% & Negative Control & Positive Control & Tr. Pr-IONPS Group & Tr. Dimi Group \\
\hline 0.0 & $64.00 \pm 1.77^{\mathrm{B}}$ & $68.75 \pm 2.25^{\mathrm{A}}$ & $62.25 \pm 1.18^{\mathrm{B}}$ & $65.00 \pm 1.41^{\mathrm{AB}}$ \\
0.1 & $59.00 \pm 1.47^{\mathrm{C}}$ & $66.25 \pm 2.21^{\mathrm{A}}$ & $57.50 \pm 0.86^{\mathrm{C}}$ & $60.25 \pm 1.03^{\mathrm{B}}$ \\
0.3 & $56.00 \pm 1.77^{\mathrm{C}}$ & $68.25 \pm 2.49^{\mathrm{A}}$ & $56.75 \pm 2.46^{\mathrm{C}}$ & $61.00 \pm 1.95^{\mathrm{B}}$ \\
0.5 & $53.25 \pm 1.70^{\mathrm{D}}$ & $66.25 \pm 1.65^{\mathrm{A}}$ & $53.75 \pm 1.37^{\mathrm{D}}$ & $58.25 \pm 2.86^{\mathrm{C}}$ \\
0.7 & $11.75 \pm 1.18^{\mathrm{L}}$ & $18.25 \pm 1.37^{\mathrm{K}}$ & $6.95 \pm 2.31^{\mathrm{M}}$ & $9.72 \pm 3.06^{\mathrm{L}}$ \\
0.9 & $4.50 \pm 0.28^{\mathrm{N}}$ & $8.00 \pm 0.40^{\mathrm{M}}$ & $3.50 \pm 0.28^{\mathrm{N}}$ & $4.50 \pm 0.64^{\mathrm{N}}$ \\
\hline
\end{tabular}

Different letters denoted significant differences at $(\mathrm{P}<0.05)$. $\mathrm{N}=5$. (LSD: 4.59). 


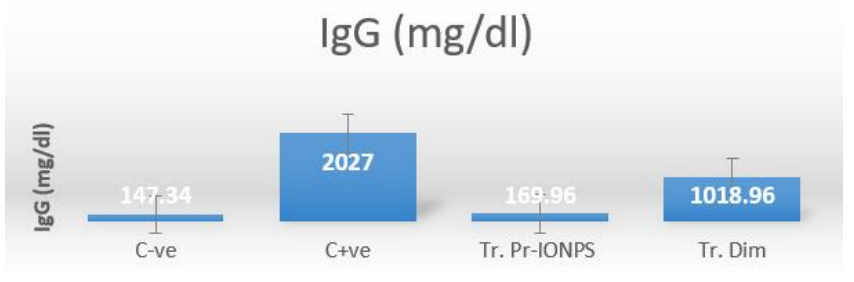

Figure 2: Effects of Pr-IONPS treatment on IgG protein of experimentally trypanosomiasis compared with diminazean drug.

\section{Discussion}

Anemia is one of the main symptoms caused by trypanosomiasis $(3,14,15)$, therefore, stress, weakness, hair loss, fatigue, and low body weight in affected rabbits were clear as a results of iron deficiency anemia. The protective role of Pr-IONPS synthesized by propolis extracts was clearly demonstrated by gradually absent the clinical signs and the body weight back toward normal and showed the improvement in their health condition during the period of treatment, as a result of potential replacement of iron and efficient enough to homeostasis iron to normal level (10). Intramuscular dose of a diminazene drug was shown to be highly active against trypanosome, but when compared with Try-Pr-IONPs group, the results of present study cleared the effects of Pr-IONPS is more efficient than diminazene drug as a treatment to reward the body weight and removed the clinical signs of diseases from the animals. Host with trypanosomiasis suffering from anemia may directly or indirectly suppress host erythropoiesis $(16,17)$. The treatment of infected rabbits with Pr-IONPs turn two directions, the first is to eliminate the parasite and the second restore homeostasis iron status parameters to the natural environment. There are many trials for treatment and control parasitic diseases by new strategies, here applying nanotechnology is the best candidate. Improvements are needed in drug administration and formulations to treat parasitic infections and with less toxicity to the host. The trypanocidal effects of Pr-IONps used in the present study could be attributed to parasite necrosis caused by iron elements, as have been noticed in using silver nanoparticles (18).

Trypanosomiasis infection causes dysregulation in oxidant / antioxidant status of infected animals, result in lipid peroxidation of RBCs membrane $(17,19)$. On this regard, The $T$. evansi caused the increase of osmotic fragility and injury of the erythrocytes. Increased bilirubin in circulation demonstrated increased red blood cells hemolysis. Infected mammals such as buffalo, dogs, rats and rabbits with $T$. evansi suffered from increased total bilirubin, conjugated and unconjugated bilirubin in the serum (20). Propolis used in the biosynthesis of IONPs is rich in polyphenols compound exert antioxidant activities (21). These abnormal changes in RBCs caused anemia denoted in the present study (22). Taken together, data obtained from the present study suggest that Pr-IONPS has anti-trypanosoma as well as diminazene did (23), furthermore it's act as antioxidant thus removing and treating the main cause of the red blood cells hemolysis and rises total bilirubin level Using radial immunodiffusion (RID) plates for the quantitation of immunoglobulins IgG determination can be used in cases of parasitic diseases diagnosis. The reduction of $\mathrm{IgG}$ in $\mathrm{Pr}-$ IONPs treated rabbits considered as marker for the immunomodulatory role, similar hyper immunoglobulinemia were noticed in naturally infected camels, in both acute and chronic stages of the disease $(7,24)$.

\section{Conclusion}

The present results showed that Pr-IONPs are safe, have anti-trypanosoma activity and reverse iron status, red cell membrane integrity, and immunomodulatory markers associated with $T$. evansi experimentally infection

\section{Acknowledgments}

Authors are grateful to the staff working in the abattoir of Al- Najaf provinces, for their facilitating the collection of camels blood samples for parasite isolation

\section{Conflict of Interests}

The manuscript has been approved by all the co-authors and declare that there is no conflict with any other

\section{References}

1. Benfodil K, Büscher P, Abdelli A. Comparison of serological and molecular tests for detection of Trypanosoma evansi in domestic animals from Ghardaïa district, south Algeria. Vet Parasitol .2020;280:109089. DOI: 10.1016/j.vetpar.2020.109089

2. Mohammed NH. Study on the blood protozoa in gees. Iraqi J Vet Sci. 2020;34(1):23-27. DOI: $10.33899 /$ ijvs.2019.125499.1028

3. Neves JV, Gomes AC, Costa DM, Barroso C, Vaulont S, Cordeiro da Silva A, Tavares J, Rodrigues PNS. A role of hepcidin in the anemia caused by Trypanosoma brucei Infection. Haematol. 2021;106(3):806818. DOI: $10.3324 /$ haematol.2019.227728

4. Kariuki CK, Stijlemans B, Magez S. The trypanosomal transferrin receptor of Trypanosoma brucei-A review. Trop Med Infect Dis 2019;4(4):126. DOI: 10.3390/tropicalmed4040126

5. Volpedo G, Costa L, Ryan N, Halsey G, Satoskar A, Oghumu S. Nanoparticulate drug delivery systems for the treatment of neglected tropical protozoan diseases. J Venom Anim Toxins Incl Trop Dis. 2019;25. DOI: 10.1590/1678-9199-JVATITD-1441-18

6. Gondim BL, da Silva Catarino G, de Sousa MD. Nanoparticle-mediated drug delivery: Blood-brain barrier as the main obstacle to treating infectious diseases in CNS. Curr Pharmaceut Design. 2019;25(37):3983-3996. DOI: 10.2174/1381612825666191014171354

7. Hassan MG, Abdullah TA. The effect of propolis addition to broiler feeds on some blood biochemical parameters and intestinal flora. Iraqi J Vet Sci. 2020;34(1):29-35. DOI: 10.33899/ijvs.2019.125483.1015 
8. Amisigo CM, Antwi CA, Adjimani JP, Gwira TM. In vitro Antitrypanosomal effects of selected phenolic acids on Trypanosoma brucei. PLoS One. 2019;14(5):e0216078. DOI: 10.1371/pone.0216078

9. Eldakroury MF, Darwish AA. Comparative pharmacological study on moxidectin and propolis ointment in rabbits naturally infested with Psoroptes cuniculi. Iraqi J Vet Sci. 2021;35(4):725-731. DOI: 10.33899/ijvs.2021.128171.1560

10. Al-Hussain RS, Al-Qayim MA. In vivo study the effectiveness of novel biogenic Pr-IONPs in rehomeostasis iron mechanisms in iron deficiency anemia. J Pharmaceut Sci Res. 2018;10(8):2007-13. [available at]

11. Prayag K, Surve DH, Paul A. Nanotechnological interventions for treatment of trypanosomiasis in humans and animals. Drug Del Transl Res. 2020;10(4):945-961. DOI: 10.1007/s13346-020-00764-X

12. Al-Hussain RS, Al-Qayim MJ. Biosynthesis of magnetite iron oxide nanoparticles mediated. IOSR J Pharm Biol Sci. 2017;12(6)65-73. [available at]

13. Yamanishi H, Kimura S, Iyama S, Yamaguchi Y, Yanagihara T. Fully automated measurement of total iron-binding capacity in serum. Clin Chem. 1997;43(12):2413-2417. [available at]

14. Rivera-Correa J, Verdi J, Sherman J, Sternberg JM, Raper J, Rodriguez A Autoimmunity to phosphatidylserine and anemia in African Trypanosome infections. PLoS Negl Trop Dis. 2021;15(9):e0009814. DOI: 10.1371/journal.pntd.0009814

15. El Aid Kaaboub NO, Nadjet AO, Ali D, Imene O, Asma H, Djamel K. Investigation of the principal vectors of abortive diseases in onehumped camels (Camelus dromedarius). Iraqi J Vet Sci. 2021;35(3):411-415. DOI: 10.33899 /ijvs.2020.126914.1415

16. McAllister M, Phillips N, Belosevic M. Trypanosoma carassii Infection in Goldfish (Carassius auratus L.): Changes in the expression of erythropoiesis and anemia regulatory genes. Parasitol Res. 2019;18(4):1147-1158. DOI: 10.1007/s00436-019-06246-5

17. Brito TK, Viana RL, Moreno CJ. Synthesis of silver nanoparticle employing corn cob xylan as a reducing agent with anti-Trypanosoma cruzi activity. Int J Nanomed. 2020;15:965-979. DOI: 10.2147/IJN.S216386

18. Wolkmer P, da Silva AS, Traesel CK. Lipid peroxidation associated with anemia in rats experimentally infected with Trypanosoma evansi. Vet Parasitol. 2009;165(1-2):41-6. DOI: 10.1016/j.vetpar.2009.06.032

19. Mateus F, Anielen D, Nathieli B. Resveratrol impacts in oxidative stress in liver during Trypanosoma cruzi infection. Microbial Pathol. 2021;153:10-15. DOI: 10.1016/j.micpath.2021.104800

20. Hilali M, Abdel-Gawad A, Nassar A, Abdel-Wahab A. Hematological and biochemical changes in water buffalo calves (Bubalus bubalis) infected with Trypanosoma evansi. Vet Parasitol. 2006;139(1-3):23743. DOI: $10.1016 /$ j.vetpar.2006.02.013

21. Yanet K, Diego A, Yamul EL. Co-crystallized sucrose with propolis extract as a food ingredient: Powder characterization and antioxidant stability. LWT. 2021;143:63-70. DOI: 10.1016/j.1wt.2021.111164

22. Al-Badrani BA. Common causes of anemia in Mosul. Iraqi J Vet Sci. 2005;19(1):33-41. DOI: 10.33899/ijvs.2005.37284

23. Okwor $\mathrm{OH}$, Ogugua VN, Okagu IU. therapeutic evaluation of antitrypanosoma activity of ethanol extracts of Jatropha curcas roots in comparison with diminazene aceturate in Trypanosoma brucei parasitized rats. Comp Clin Pathol. 2020;29:1189-1198. DOI: 10.1007/s00580-020-03171-3

24. Mohammed RS, Donia GR. Immunological and histopathological alterations in rats experimentally infected with Trypanosoma evansi. $\mathrm{J}$ Anim Hlth Prod. 2019;7(2):43-50. DOI: 10.17582/journal.jahp/2019/7.2.43.50

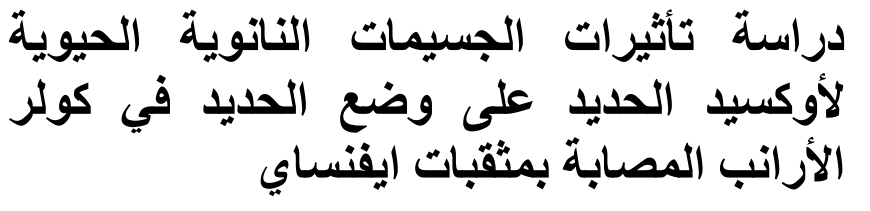

ماجدة عبدالخالق القيم'، لازم حميد الطائيَ و غيث صادق غالي ‘

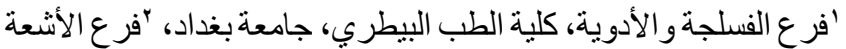

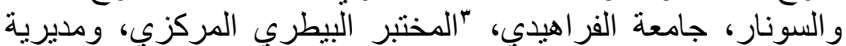

زر اعة بغداد، بغداد، العراق جات الفئ

الخلاصة

هدفت الدر اسة الحالية لتقييم تأثير الجسيمات النانوية لأوكسيد الحديد

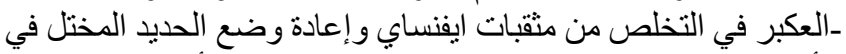

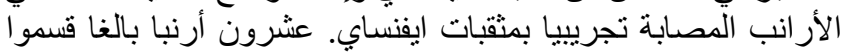

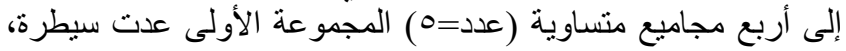

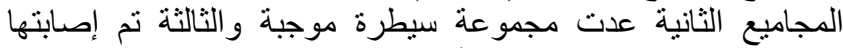

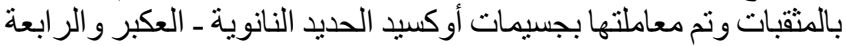

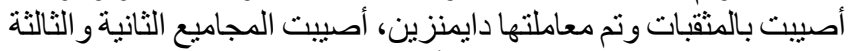

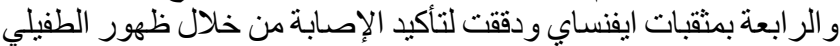

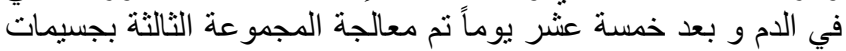

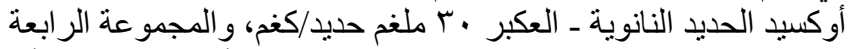

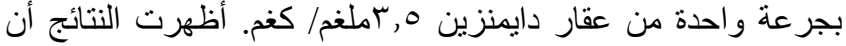
الإصابة التجريبية بمثقبات ايفنساي سبب التخفاض داض في في نركيز الحديد في

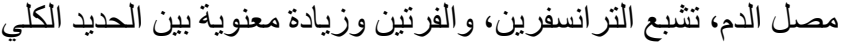

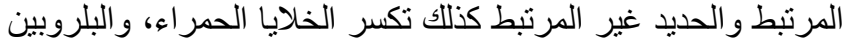
الكلي و الجزئي. إن العلاج بالأوكسيد الحديد النانوي ـ العكبر رفع تركيز

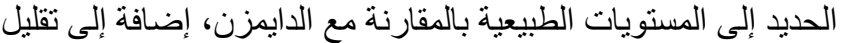

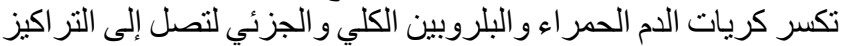

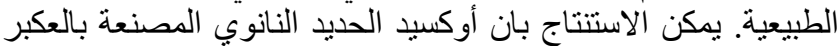
حسنت بنجاح و إعادة تو ازن الحديد و التخلص من الطفيلي وتوفير الحديد

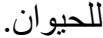

